\title{
Studies on cell adhesion and Concanavalin A-induced agglutination of Candida albicans after mannan extraction
}

\author{
R. L. SANDIN
}

Department of Botany and Plant Pathology, Michigan State University, East Lansing, Michigan 48824, USA

\begin{abstract}
Summary. Candida albicans cells were treated with alkali and acid to extract preferentially the cell wall $\alpha$-mannan. Cells were recovered at three stages, as extraction proceeded from mild to more extensive: Alk-1, Alk-2 and Alk + Acid. Yeast adhesion to human epithelial cells was then examined with an in-vitro adherence assay. Yeasts from all three stages of extraction adhered in significantly lower numbers to buccal mucosal cells than did unextracted yeasts. Adhesion was as low for Alk-1 cells as for those submitted to more complete mannan extraction. When yeast cells from all three stages were treated with Concanavalin A (Con A), a lectin probe with strong affinity for yeast $\alpha$-mannans, and then subjected to the adherence assay, there was no significant change in adhesion. When yeast agglutinability by Con A was examined in tests with treated and untreated yeast cells, abundant agglutination occurred only with the untreated cells. However, Alk-1 cells, though lacking in adhesive capacity towards mucosal cells, showed significant agglutination. The results suggest that candidal adhesion is mediated by an alkali-soluble, mannancontaining moiety(ies) which appears to be lost early in the extraction process. Blockage of this moiety by Con A inhibits the adhesion of unextracted cells. Extracted cells lack this moiety but still possess enough structural mannan for Con A recognition and agglutination.
\end{abstract}

\section{Introduction}

For a microbe such as Candida albicans to survive on the mucous membranes of a host, a specific means of adhesion and anchorage is assumed to prevent its dislodgement and eradication from the body. Many recent studies have examined the nature of the adhesive moiety on the surface of $C$. albicans (Lee and King, 1981; Maisch and Calderone, 1981 ; McCourtie and Douglas, 1981 ; Sobel et al., 1981; Sandin and Rogers, 1982; Sandin et al., 1982; Segal et al., 1982; Douglas and McCourtie, 1983; Lee and King, 1983; Tronchin et al., 1984; McCourtie and Douglas, 1985). There is marked controversy, but many of these studies suggest that $\alpha$-mannan mediates candidal adhesion.

The present study extends the previous finding that treatment of yeasts with the lectin Concanavalin $\mathrm{A}$ (Con $\mathrm{A}$ ) before mixing with mucosal cells blocks adhesion (Sandin and Rogers, 1982). It was postulated that the lectin binds to a mannancontaining adhesin on the yeast surface and blocks it (Sandin et al., 1982). This study applied the cell

Received 21 Jul. 1986; revised version accepted 21 Oct. 1986. wall mannan extraction procedure of Cassone $e t$ al. (1978) to the study of adhesion in C. albicans. Although those researchers examined the wall ultrastructure of yeast cells submitted to this procedure, the technique was not exploited by them to evaluate the adhesive capacity of the extracted cells.

\section{Materials and methods}

\section{Buccal mucosal cells}

Buccal cells were collected by gently rubbing the inside cheek area of one healthy adult volunteer with sterile swabs and swirling the swabs in phosphate-buffered saline $(0.01 \mathrm{M}$ sodium phosphate dibasic in normal saline,

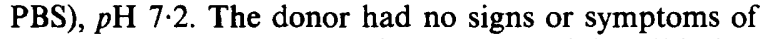
oral thrush and was not taking antibacterial antibiotics. The cells were washed three times in PBS and then suspended to concentrations of $2 \times 10^{5}$ cells $/ \mathrm{ml}$ of PBS, as determined with a haemocytometer.

When examined by light microscopy before experimentation, none of the cell samples used in this study contained mucosal cells already colonised by yeasts. All experiments were done with cells from one donor to 
reduce, as far as possible, the heterogeneity of the mucosal cells.

\section{Yeast cells}

C. albicans strain MSU-1, previously isolated from a patient with thrush, was grown on slants of Sabouraud Dextrose Agar (BBL, Cockeysville, MD, USA) for $48 \mathrm{~h}$ at $37^{\circ} \mathrm{C}$. A loopful of cells was transferred to $100 \mathrm{ml}$ of Trypticase Soy Broth (BBL) plus glucose $4 \% \mathrm{w} / \mathrm{v}$ and incubated at $37^{\circ} \mathrm{C}$ on a rotary shaker $(180 \mathrm{rpm})$ for $13 \mathrm{~h}$ for the culture to develop into the stationary phase. A sample was removed, washed three times in PBS, and then resuspended in tissue culture medium M199 (Gibco Laboratories, Santa Clara, CA, USA) adjusted to $p \mathrm{H} \mathrm{7 \cdot 2.}$ The suspension was incubated for $1 \mathrm{~h}$ at $37^{\circ} \mathrm{C}$ to allow germ tubes to develop.

Most yeast cells ( $>95 \%$ ) possessed germ tubes after the treatment. Unless otherwise indicated, all experiments were performed with germinated yeast cells because they were previously shown to adhere in greater numbers to mucosal cells than non-germinated ones at the same concentrations (Kimura and Pearsall, 1980; Sandin et al., 1982). Formaldehyde treatment of yeast cells did not change their adherence significantly. Stationary-phase cells were used in this study because they have been shown to adhere more readily than logarithmic-phase cells (Kimura and Pearsall, 1978; King et al., 1980).

\section{Extraction of polysaccharides from the cell wall of $C$. albicans}

The previously described procedure (Cassone et al., 1978 ) was used to extract preferentially the $\alpha$-mannan from the cell wall in a sequential manner. Briefly, following germination in medium M199, the yeast-cell suspension was divided into two aliquots: no. 1, the control cell suspension, was treated with formaldehyde $0.5 \%$ in PBS, $p \mathrm{H} 7.2$, for $30 \mathrm{~min}$ at $4^{\circ} \mathrm{C}$; the cells were then washed twice in PBS, resuspended to a concentration of $1 \times 10^{6} \mathrm{cells} / \mathrm{ml}$ and kept on ice. No. 2 was submitted to the extraction procedure: the cells were washed twice in PBS, resuspended in $1 \mathrm{M} \mathrm{NaOH}$ and incubated at room temperature in a shaker for $45 \mathrm{~min}$; these are referred to as Alk-1 cells.

One-third of the Alk-1 cell suspension was washed three times in PBS, treated with formalin and re-washed twice in PBS, resuspended to $1 \times 10^{6}$ cells $/ \mathrm{ml}$ in PBS and kept on ice. The other two-thirds of the Alk-1 cell suspension were submitted to a more drastic extraction process with alkali. The cells were resuspended in $0.6 \mathrm{M} \mathrm{NaOH}$ and heated at $85^{\circ} \mathrm{C}$ for five periods of $4 \mathrm{~h}$ each. At the end of every $4-\mathrm{h}$ period, the cells were centrifuged and new solvent was added. After the last 4-h period, new solvent was added and the cells were incubated overnight at room temperature. These cells are referred to as Alk-2 cells.

One-half of the Alk-2 cell suspension was washed three times in PBS, treated with formalin, re-washed twice in PBS, and resuspended in PBS to $1 \times 10^{6}$ cells $/ \mathrm{ml}$. These cells were kept on ice. The other half was submitted to acid extraction for $12 \mathrm{~h}$ with $0.5 \mathrm{M}$ acetic acid at $85^{\circ} \mathrm{C}$. Cells were washed in PBS every $4 \mathrm{~h}$ and resuspended in acetic acid. After extraction with acid, the cells were washed, treated with formalin, re-washed, and resuspended in PBS to a concentration of $1 \times 10^{6}$ cells $/ \mathrm{ml}$. This is referred to as the Alk + Acid cell preparation.

\section{In-vitro adherence assay}

Adherence of $C$. albicans was studied as described by Sandin et al. (1982). Briefly, 0.2-ml samples of buccal and yeast cells (ratio of yeast to buccal cells, 5:1) were pipetted into tubes $(12 \times 75 \mathrm{~mm})$ and incubated on a shaker at $180 \mathrm{rpm}$ for $1 \mathrm{~h}$ at $37^{\circ} \mathrm{C}$. Three tubes were used for each control and for each experimental test, followed by repetitions of each experiment. Polycarbonate filters (12 $\mu \mathrm{m}$ pore size; Nucleopore Corp., Pleasanton, CA, USA) were used for collection of the adherence test mixtures from each tube and washed with $100 \mathrm{ml}$ of PBS with continuous agitation. Filters of this pore size allowed the non-adherent yeasts to pass through while retaining those adhering to buccal cells. The filters were stained with Gram's crystal violet, and the number of yeasts adhering to 200 buccal cells was determined by light microscopy at a magnification of 430 . Double-blind observer conditions were applied to all studies.

\section{Con A pretreatment of extracted cells}

Before the adherence assay, samples from each of the controls, Alk-1, Alk-2 and Alk + Acid cell preparations were treated with Con A (ICN Pharmaceuticals, Cleveland, OH, USA), as follows. Samples $(2 \mathrm{ml})$ of standardised cells were centrifuged, resuspended in $5 \mathrm{ml}$ of lectin solution, and incubated at room temperature for $45 \mathrm{~min}$ on a shaker $(180 \mathrm{rpm})$. The lectin solution contained Con A $10 \mu \mathrm{g} / \mathrm{ml}$ in PBS, $p \mathrm{H} 7 \cdot 2$, with added cations $(0.002 \mathrm{M}$ magnesium, calcium and manganese salts). Thereafter, the cells were washed, resuspended in PBS to $2 \mathrm{ml}$, and mixed with buccal cells for the adherence assay. Although Con A is a yeast agglutinin, as observed in the slide agglutination tests, yeast agglutination was never observed in adhesion systems either during cell pretreatment with lectins or during the $1-h$ adherence assay. This can be attributed to the fact that all steps were performed in conditions of continuous agitation with low, sub-agglutinating concentrations of Con A. Continuous agitation was also used to wash the cells that had been collected on filters after the adherence assay.

\section{Slide agglutination assay of yeasts with Con $A$}

The susceptibilities of unextracted and extracted cells to agglutination by Con A were compared in slide agglutination tests. Cells from each step in the extraction 
process, as well as control (unextracted) cells, were used in individual assays. Briefly, a drop of yeast-cell suspension $\left(1 \times 10^{7}\right.$ cells $/ \mathrm{ml}$ of PBS $)$ was placed on a glass slide and a drop of Con A solution, $1 \mathrm{mg} / \mathrm{ml}$ of PBS, was placed on top of it. Both drops were mixed well with a wooden stick and incubated at room temperature for $5 \mathrm{~min}$ with gentle rocking. Each slide was then evaluated by microscopy for agglutination on a scale of 0 to $10:$ a score of 10 corresponded to abundant agglutination, the field being filled with clusters of 15 or more yeasts; a score of 1 denoted minimal agglutination with very few clusters of yeast cells. Scores between 1 and 10 were assigned by comparison within those extreme values. As a negative control, PBS without added lectin was substituted for the lectin solution as the second drop in the assay; these tests scored 0 . Tandem slides were then prepared with extracted and unextracted yeast cells, followed by repetitions of the slide assay.

To ascertain that formalin treatment did not interfere with yeast agglutination, the ability of Con A to agglutinate $C$. albicans cells in four states was evaluated. Live non-germinated, live germinated, dead non-germinated, and dead germinated yeasts were used. The germination and formalin-killing procedures were as already described. In controls PBS was used instead of the lectin solution.

\section{Statistical evaluation of the data}

Results from these experiments were evaluated by Student's $t$ test.

\section{Results}

Adherence of alkali and acid-extracted C. albicans to buccal mucosal cells, and the effect of Con A on yeast adhesion

The effect of alkali and acid extraction on yeast adherence to mucosal cells was evaluated (table). Both stages in the alkali extraction process, as well as the subsequent acid extraction, significantly diminished the adherence of $C$. albicans. Adherence was as low for cells submitted to the milder Alk-1 treatment as for those subjected to the stronger Alk-2 and Alk + Acid steps. Pretreatment of nonextracted control cells with Con A led to a significant decrease in adherence, in accordance with previous reports (Sandin and Rogers, 1982; Sandin et al., 1982). This inhibition was specific as verified by a hapten inhibition test with the mannose derivative, $\alpha$-D-methylmannoside ( $\alpha$-D-mM). Prior exposure of Con $A$ to this sugar removed the inhibitory effect of Con A on yeast adherence, whereas pretreatment of Con A with other sugars, such as galactose or ribose, did not (data not shown). However, Con A pretreatment of cells from any of the three stages of extraction did not produce any further significant changes in the numbers of adhering yeasts.

\section{Agglutination of extracted and unextracted C. albicans by Con $A$}

A slide agglutination assay was performed with Con A and cells from each step in the extraction process. Qualitative evaluation was performed visually on a scale from 0 to 10 . No agglutination (0) was observed when PBS was used instead of the lectin solution with cells from each step of extraction. However, when Con A solution was used, unextracted cells showed abundant agglutination (10) and Alk-1 cells showed intermediate to high agglutination scores (7). Agglutination diminished in tests with cells from each successive stage of the extraction process, with a value of 2 for Alk- 2 cells and minimal agglutination (1) with Alk + Acid cells.

Repetition twice of the slide assays yielded consistent results, which also confirmed findings reported in the paper that described the mannan extraction procedure (Cassone et al., 1978).

Table. Effect of alkali and acid extraction, and Con A pretreatment, on the adherence of germinated C. albicans to buccal mucosal cells

\begin{tabular}{|c|c|c|c|c|}
\hline Treatment* & $\begin{array}{l}\text { Number of adhering yeasts } / 200 \text { buccal } \\
\text { cells (percentage adherence) }\end{array}$ & $\begin{array}{l}\text { Probability } \dagger \\
\text { (P) }\end{array}$ & $\begin{array}{l}\text { Number of adhering yeasts when pre- } \\
\text { treated with Con A (percentage adher- } \\
\text { ence) }\end{array}$ & $\begin{array}{l}\text { Probability } \ddagger \\
\text { (p) }\end{array}$ \\
\hline Control & 305 SEM $0.63(100)$ & & 54 SEM 0.61 (17) & $<0.001$ \\
\hline Alk-1 & 6 SEM 0.23(1.9) & $<0.001$ & 6 SEM $2.74(1.9)$ & NS \\
\hline Alk-2 & 6 SEM $1.41(1.9)$ & $<0.001$ & 4 SEM $0.29(1 \cdot 3)$ & NS \\
\hline Alk + Acid & 3 SEM $1 \cdot 16(0.98)$ & $<0.001$ & 4 SEM $2 \cdot 18(1 \cdot 3)$ & NS \\
\hline
\end{tabular}

\footnotetext{
* See Methods.

$\dagger$ Compared with the control.

$\ddagger$ Compared with their non-pretreated counterparts.
} 
Influence of yeast viability or state of germination on agglutination by $\operatorname{Con} A$

When $C$. albicans cells in four states (live nongerminated, live germinated, dead non-germinated and dead germinated yeasts) were submitted to agglutination assays with Con A, all four types were agglutinated well, while PBS did not agglutinate any yeasts (data not shown). Thus, formalin treatment and the state of germination do not appear to influence yeast agglutination by Con $\mathrm{A}$.

\section{Discussion}

Three polysaccharides make up the bulk of the cell wall of $C$. albicans: $\alpha$-mannan, $\beta$-glucan and chitin (Bishop et al., 1960). During recent years many workers have tried to identify the role that these compounds might play in mediating candidal adhesion (see Introduction). In studies with various lectins, only Con A significantly decreased the adherence of $C$. albicans to mucosal cells (Sandin and Rogers, 1982; Sandin et al., 1982). By correlating the known carbohydrate-binding properties of Con A (Goldstein et al., 1965) with these and other experimental results (Lee and King, 1981; Maisch and Calderone, 1981; McCourtie and Douglas, 1981; Sandin and Rogers, 1982; Sandin et al., 1982), it was concluded that mannose-containing moieties on the yeast surface might serve as mediators of adhesion to mucosal epithelia (Sandin et al., 1982). The present study was designed to investigate this proposition further.

Yeast cells submitted to extraction with alkali and acid adhere in significantly lower numbers than unextracted (control) cells to buccal mucosal cells. Adhesion scores for yeast cells submitted to the milder alkali treatment (Alk-1) were as low as those for yeast cells submitted to further and more complete mannan extraction (Alk-2 and Alk+ Acid). This suggests that in unextracted cells the substance mediating abundant adhesion is either very labile to alkali hydrolysis or has a superficial cell-wall location so that the mild alkali treatment undergone by Alk-1 cells removes most of it. The other two stages extract most or all of the remaining mannan and a small amount of soluble $\beta$-glucan (Cassone et al., 1978), thus leaving the inner glucan and chitin matrix exposed. Were these latter two components the yeast adhesin, cells in the Alk + Acid stage could be expected to adhere in high numbers to mucosal cells, rather than in such low numbers. Thus, the present findings once more suggest that a mannose-containing moiety is the mediates candidal adherence.
The adhesiveness of unextracted Candida cells pretreated with Con A was markedly reduced in tests with buccal epithelial cells. When the yeast cells sampled at each of the three stages of extraction were treated with Con $A$ and then tested for adherence to buccal cells, they showed no further significant changes in their already markedly low adherence values. This indicates that Con A inhibits yeast adherence by binding to an alkalisoluble component present in control cells but absent from extracted cells. The finding that nongerminated yeasts adhere in lower numbers than germinated yeasts to mucosal cells (Sandin et al., 1982) suggests that this component is concentrated on the germ tube surface.

Cells at different stages of extraction were submitted to slide agglutination assays with Con $\mathrm{A}$. The conditions used in slide assays differed from those used during yeast treatment before adherence assays in that higher concentrations of Con A were used in slide assays, in combination with gentle rocking of the slides. It was not surprising that unextracted yeast cells underwent abundant agglutination with Con $\mathrm{A}$, because yeast mannan is the polysaccharide that is most tenaciously bound by Con A (Goldstein et al., 1965). Likewise, it was not a surprise that Alk + Acid cells underwent minimal or no agglutination, because Con A-mediated agglutination occurs in direct proportion to the amount of cell-wall mannan present (Cassone et al., 1978). However, it is remarkable that Alk-1 cells, devoid of most of their adhesive capacity for mucosal cells, still agglutinated significantly with Con A. Although lacking the mannose-containing complex that mediates adhesion, these cells possess sufficient cell-wall mannan to serve as substrate for Con A recognition and agglutination.

Although the experiments reported in the table were performed with strain MSU-1, identical experiments were done with two other strains previously isolated from patients with thrush. The results of adherence and agglutination assays with these strains were very similar to those reported in the text. Experiments were repeated three or more times and the findings were highly reproducible. This is reassuring in light of the arguments raised by Rosenstein et al. (1985) on the reproducibility of data obtained from adhesion assays. They performed adhesion assays with 18 mucosal-cell samples derived from one large batch of mucosal cells and found that the number of microbes attached to 50 mucosal cells varied significantly between samples. Such differences were not observed in the present study, even though some of the experiments were repeated many times. Perhaps the use of 200 
mucosal cells, rather than 50 , in each adhesion assay contributed to the greater uniformity of results.

Although a large number of workers have used blastospores to study adhesion, it seems reasonable to explain why germ tube forms were selected for this study because germinated forms attach in much larger numbers than yeast forms (Sandin et al., 1982), suggesting that the adhesive moiety(ies) could be concentrated on the germ tube surface. Furthermore, in tissues where colonisation has progressed to frank infection, filamentous (mycelial) elements are invariably present. The yeast with germ tube constitutes the intermediate stage between the blastospore and these filamentous (hyphal) elements. Experiments in progress have also shown that several media reported to produce blastospores actually yield spores with minuscule, almost imperceptible, germ tubes. These were very sticky cells and might easily be classified as ungerminated blastospores by non-discriminating observers.

It is reasonable to suggest that yeast cell walls contain a range of mannan-containing complexes. The term "structural mannan" could be applied to the bulk of the wall mannan that serves a key function in the production of layers within the cell wall and survives mild alkali treatment. The term "functional mannan" could denote one or more independent moiety(ies) that participate in adhesion but are eluted by mild alkali treatment.

\section{REFERENCES}

Bishop C T, Blank F. Gardner P E 1960 The cell wall polysaccharides of Candida albicans: glucan, mannan and chitin. Canadian Journal of Chemistry 38, 869-881.

Cassone A, Mattia E, Boldrini L 1978 Agglutination of blastospores of Candida albicans by Concanavalin A and its relationship with the distribution of mannan polymers and the ultrastructure of the cell wall. Journal of General Microbiology 105, 263-273.

Douglas L J, McCourtie J 1983 Effect of tunicamycin treatment on the adherence of Candida albicans to human buccal epithelial cells. FEMS Microbiology Letters 16: 199-202.

Goldstein I J, Hollerman C E, Merrick J M 1965 Proteincarbohydrate interaction. I. The interaction of polysaccharides with Concanavalin A. Biochimica et Biophysica Acta 97: 68-76.

Kimura L H, Pearsall N N 1978 Adherence of Candida albicans to human buccal epithelial cells. Infection and Immunity $\mathbf{2 1}$ : 64-68.

Kimura L H, Pearsall N N 1980 Relationship between germination of Candida albicans and increased adherence to human buccal epithelial cells. Infection and Immunity 28 : 464-468.

King R D, Lee J C, Morris A L 1980 Adherence of Candida
Blockage of the postulated adhesin(s) on unextracted yeasts by Con $\mathrm{A}$ inhibits adhesion significantly. The absence of the moiety(ies) from extracted yeasts, however, prevents Con A from altering significantly their already markedly low adhesiveness. Until many of the unknown factors in the process of candidal attachment are defined, it must be assumed that more than one independent system of adhesion exists in C. albicans. Careful analysis of the extract from Alk-1 cells could reveal whether more than one peak fraction shows independent adhesive activity.

As well as decreasing the amount of "functional" mannan, the extraction process could disturb the organisation of the remaining wall mannan and further reduce the yeast cell's capacity to attach. There is electronmicroscopic evidence for this disturbance (Cassone et al., 1978).

Data from other laboratories also suggest that surface mannoproteins help to mediate candidal adherence (Lee and King, 1981; Maisch and Calderone, 1981; Douglas and McCourtie, 1983; Lee and King, 1983; Tronchin et al., 1984; McCourtie and Douglas, 1985). Work is in progress to determine how this initial process of adhesion leads to a more firm yeast attachment and anchorage.

I thank Drs E. S. Beneke and A. L. Rogers for allowing laboratory space for this research project.

albicans and other Candida species to mucosal epithelial cells. Infection and Immunity 27: 667-674.

Lee J C, King R D 1981 Characterization of surface components which mediate Candida albicans adherence to mucosal cells. Abstracts of the Annual Meeting of the American Society for Microbiology, 313.

Lee J C, King R D 1983 Characterization of Candida albicans adherence to human vaginal epithelial cells in vitro. Infection and Immunity 41 : 1024-1030.

Maisch P A, Calderone R A 1981 Role of surface mannan in the adherence of Candida albicans to fibrin-platelet clots formed in vitro. Infection and Immunity 32: 92-97.

McCourtie J, Douglas L J 1981 Relationship between cell surface composition of Candida albicans and adherence to acrylic after growth on different carbon sources. Infection and Immunity 32 : 1234-1241.

McCourtie J, Douglas L J 1985 Extracellular polymer of Candida albicans: isolation, analysis and role in adhesion. Journal of General Microbiology 131 : 495-503.

Rosenstein I J, Grady D, Hamilton-Miller J M T, Brumfitt W 1985 Relationship between adhesion of Escherichia coli to uro-epithelial cells and the pathogenesis of urinary infection: problems in methodology and analysis. Journal of Medical Microbiology 20: 335-344.

Sandin R L, Rogers A L, Patterson R J, Beneke E S 1982 Evidence for mannose-mediated adherence of Candida 
albicans to human buccal cells in vitro. Infection and Immunity 35: 79-85.

Sandin R L, Rogers A L 1982 Inhibition of adherence of Candida albicans to human epithelial cells. Mycopathologia 77: 2326.

Segal E, Lehrer N, Ofek I 1982 Adherence of Candida albicans to human vaginal epithelial cells: inhibition by amino sugars. Experimental Cell Biology 50: 13-17.
Sobel J D, Myers P G, Kaye D, Levison M E 1981 Adherence of Candida albicans to human vaginal and buccal epithelial cells. Journal of Infectious Diseases 143: 76-82.

Tronchin G, Poulain D, Vernes A 1984 Cytochemical and ultrastructural studies of Candida albicans III. Evidence for modifications of the cell wall coat during adherence to human buccal epithelial cells. Archives of Microbiology 139: 221-224. 